\title{
Environmental accounting of buildings: outcomes from the emergy analysis
}

\author{
F. M. Pulselli, R. M. Pulselli \& E. Simoncini \\ Department of Chemical and Biosystems Sciences, \\ University of Siena, Italy
}

\begin{abstract}
In recent years, efforts have been made to promote integrated building design practices based on the definition of "green building" criteria as common standards of measurement. For example, Green Building Rating Systems such as LEED (US) and BREEAM (UK) provide national standards for developing high-performance sustainable buildings.

However, integrated environmental accounting methods are still required to evaluate the general environmental performances of buildings in the two phases of their construction and their use, relative to problems such as global resource exhaustion and energy wasting.

In this paper an emergy analysis is applied to buildings. The emergy method uses the thermodynamic basis of all forms of energy and matter and converts them into equivalents of one form of energy.

Emergy enables the account of energy and material flows for building manufacturing, maintenance and use (housing). Different materials, technologies and structural elements can be compared to each other in order to hypothesise different scenarios for future buildings. A comprehensive appraisal of the building industry and its environmental impacts is then expected.
\end{abstract}

Keywords: emergy analysis, building manufacturing, building maintenance, housing

\section{Introduction}

An environmental policy for building industry aims to maintain a high quality built environment optimizing resource use. Energy consumption, energy wasting, emissions and environmental impacts due to human activity are expected to decrease. 
Buildings work to provide specific services and maintain their performances constant in time with respect to variable context conditions (clime, temperature, humidity, sun irradiation, atmosphere, etc.).

Buildings management therefore has to take care of the interactions between buildings (non-living inert structures), and their living context (the environment and human beings). This dynamic network of relations could depend on people movements and exchanges of goods and services; it has the form of materials and energy flows.

A sustainable building therefore should be able to maintain high performance state self-adapting to its surrounding environment and according to environmental resource availability, social needs, history and landscapes quality. However, eco-buildings have the following features:

- $\quad$ they make the most of energy and materials inflows;

- $\quad$ they supply a part of their energetic need through natural processes;

- $\quad$ they use renewable and local materials;

- $\quad$ they have minimal impact on natural cycles (i.e. water cycle);

- $\quad$ they belong their environmental context (landscapes, society, history).

\section{Relevance of the building industry for environmental policy}

About $30-40 \%$ of total natural resources that are used in industrialized countries are exploited by the building industry. Almost 50\% of this energy flow is used for weather conditioning (heating and cooling) in buildings. Almost $40 \%$ of world materials consumption converts to the built environment, and about $30 \%$ of energy use is due to housing. For example, in US, a rate of 35-60\% of national energy budget is used to maintain buildings (Roodman and Lenssen [1]; Stein [2]). Since $75 \%$ of electrical supply in US is thermoelectricity, also a large amount of $\mathrm{CO}_{2}$ emission depends on housing, in addition to the emissions due to building materials production. In the E.U. the energy consumption for housing and services was 371.4 Mtoe (million tons of oil equivalent) in 2000 (Eurostat, report 1995) that is higher than other sectors such as transport and industry.

In the last few years, new sustainable building technologies have been developed and applied to new buildings or even for renewal of existing structures, in order to achieve higher energetic efficiency and to reduce energy consumption and energy wasting.

The so called eco-architecture represents an attempt to respond to global environmental problems and to reduce environmental impacts due (directly or indirectly) to the building industry. The main points are relative to:

- Natural resources exhaustion (for example non renewable resources such as oil, natural gas, raw materials).

- $\quad \mathrm{CO}_{2}$ and other greenhouse gasses emissions (air pollution).

- Soil and ground water pollution and overexploitation.

- Biodiversity decrease.

Environmental accounting methods applied to the building industry evaluate building technologies and materials, and aim to define standards for making 
choices. The ecological assessment takes into account every step of the building process "from cradle to grave", that is from the extraction of raw materials to their assemblage and use, during their life-time, until their disposal or recycle.

The accounting of energy and material flows that supply buildings manufacturing processes as well as buildings use (housing) therefore have great concern with the problem of natural resources over-exploitation and also, indirectly, of greenhouse gases emissions.

Buildings ecology calls for a comprehensive vision on natural resources management based on their real "environmental cost", which depends on their availability, regeneration rate and environmental impact (absorption of wastes), with respect to natural constraints.

\section{Indicators applied to the building industry}

An "indicator" is a tool able to give synthetic information of a more complex phenomenon with a wider sense; it works to make visible a trend or a process that is not immediately clear. Indicators simplify information often relative to multiple factors and enable to communicate and compare results.

The accounting of indicators follows different targets according to which two classes can be noted:

A. State-pressure environmental indicators account for specific parameters, through conventional physical units, to verify their compatibility with specific environmental variables; they often evaluate very localized factors based on data collected in a specific area. A firstlevel information is thus achieved but it needs to be further processed in order to achieve a synthetic information.

B. Sustainability indicators provide a general evaluation based on a comprehensive balance, integrating a multiplicity of phenomena even non homogeneous; they attempt to evaluate general behaviours according to a global sustainability viewpoint, with special reference to the problems of resource overexploitation and energy wasting.

Methods for evaluating buildings are usually based on environmental statepressure indicators. These techniques are worldwide known and developed at national levels. Examples are the Building Research Environmental Assessment Method (BREEAM in UK) and the Leadership in Energy and Environmental Design (LEED, in USA). These methods provide a list of indicators based on objective values comparing buildings performances and impacts to environmental constraints defined as sustainability threshold.

Global sustainability indicators are obtained by processing data relative to different parameters (given in mass and energy units) through thermodynamics based algorithms. Different measures can be involved in a unique synthetic balance. Examples are: Emergy analysis, Ecological footprint, Exergy assessment. 
These methods enable to study relations between buildings and their environmental context, an ecosystem. An holistic approach is thus developed (the whole is more than its parts) gathering information and providing general valuation of buildings.

\section{Introduction to the emergy analysis}

Emergy analysis (spelled with an "m") is an environmental accounting method that develops an energy systems language for the thermodynamics of open systems (Odum and Odum [3]; Odum [4]). When applied to a building, it quantifies all the natural resources used for building manufacturing, maintenance and use. Emergy analysis is concerned with quantifying the relationships between human-made systems and the biosphere.

Emergy is the available solar energy previously used up, directly and indirectly, to make a service or product (Odum [4-6]). The emergy valuation assigns a value to products and services by converting them into equivalents of one form of energy, the solar energy, that is used as the common denominator through which different types of resources, either energy or matter, can be measured and compared to each other. The unit for emergy is the solar emergy joule (sej).

The emergy of different products is assessed by multiplying mass quantities (kg) or energy quantities (Joule) by a transformation coefficient, namely transformity or specific emergy. Transformity is the solar emergy required, directly or indirectly, to make one Joule or kilogram of a product or service. Every time a process is evaluated, previously calculated transformities are used as a practical way of determining the emergy (sej) of commonly used products or services. is:

By definition, the solar emergy Bk of the flow $\mathrm{k}$ coming from a given process

$$
\mathrm{Bk}=\Sigma \mathrm{i} \text { Tri } \mathrm{Ei} \quad \mathrm{i}=1, \ldots, \mathrm{n}
$$

where $\mathrm{Ei}$ is the actual energy content of the i-th independent input flow to the process and Tri is the solar transformity of the $\mathrm{i}$-th input flow.

\section{$5 \quad$ Emergy analysis of buildings}

In this section a case study is presented with an emergy analysis applied to a building. A few other case studies exist in this field and are available in literature: Brown and Buranakarn [7]; Meillaud et al [8]; Buranakarn [9].

In this study, two phases are assessed separately: 1) building manufacturing process and maintenance; 2 ) housing: building use in time.

The building under study is a $10,000 \mathrm{~m}^{3}$ block $\left(2,500 \mathrm{~m}^{3}\right.$ are underground) for residential and office use in Castelfiorentino, near Florence (Italy). It takes 2,700 $\mathrm{m}^{2}$ flats distributed on 1 basement, 1 ground-flour and 4 floors. This building has 
the characters of a traditional contemporary building and thus is a powerful case study to provide general information about resource use due to the building industry in Italy.

In Figure 1 is shown an energy system diagram of a building with inflows of energy and materials. In the diagram two phases are shown:

1) building manufacturing: is the process of gathering and assembling materials to generate a built stock (the building) and to maintain it in time (ordinary maintenance).

2) housing: is the building use during which people live in the building and consume energy for coaling and heating, electricity, gas and water.

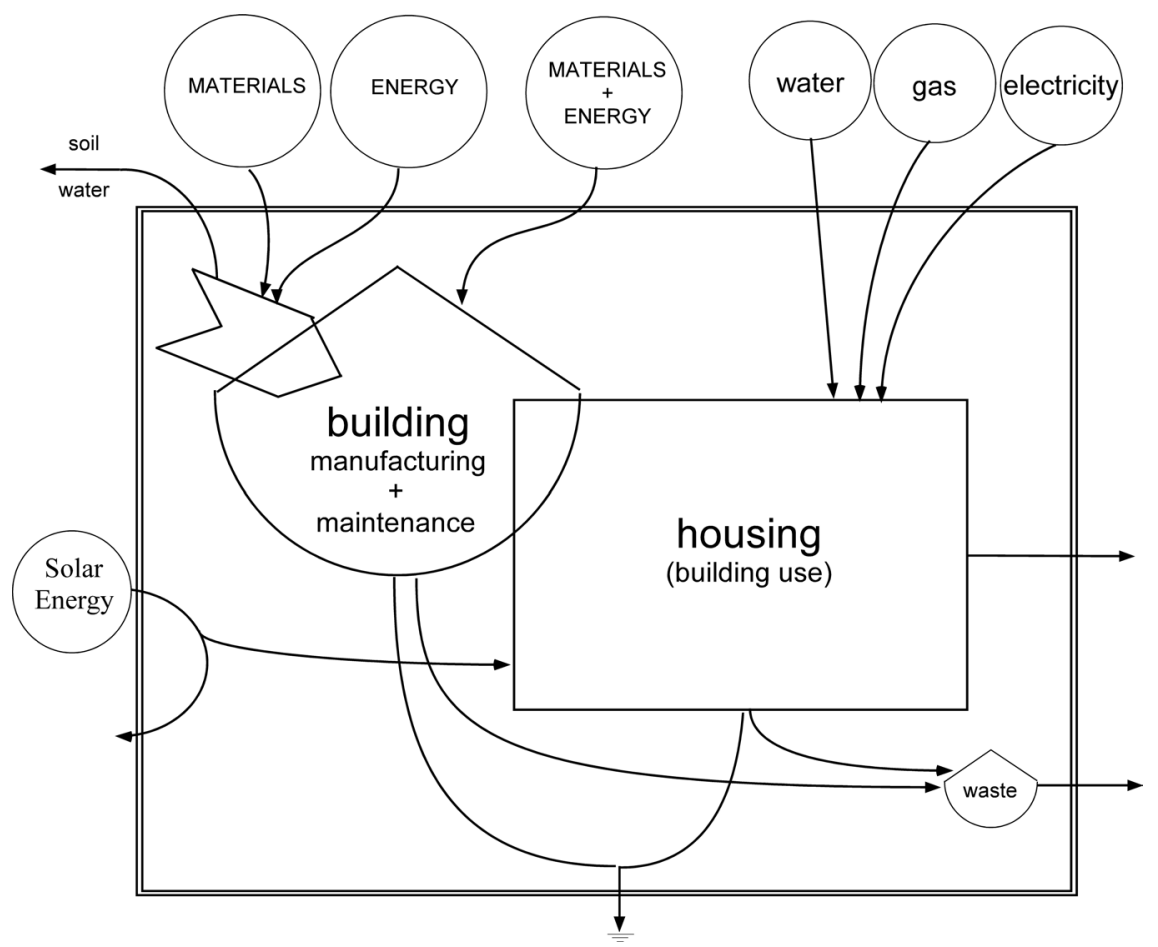

Figure 1: $\quad$ Energy system diagram of a building.

In the diagram, the interaction of different inputs, such as soil, water, energy, machinery, human work, materials, transport and other services (energy and materials flows) generates the building as a built reservoir in which energy and materials have been stocked. Also a flow of energy and materials is used for the ordinary maintenance of the building in time. In the analysis this flow is assumed to be constant for 50 years that is the likely building lifetime. The rectangle in the diagram represents the building lifetime and its function, namely housing. Housing feeds on flows of energy and matter such as electricity, water and gas.

All the inputs to the process are then assessed. Data has been collected for both the phases of building manufacturing and housing. An official document 
namely building metric computation provided by the work director gives all the quantities of materials used and human work hours for manufacturing. Data on electricity, gas and water consumptions of families has been collected for a year long period.

Every raw data (mass quantities) in the building metric computation has been expressed in terms of solar emergy joule through the transformity in order to evaluate the environmental cost of every material in the building manufacturing. Emergy flows have been aggregated into structural elements and different building parts have been compared to each other.

In Table 1, emergy flows of raw materials are presented in order to evaluate the amount of emergy stoked in the building as a reservoir. Results highlight the 'environmental cost' in terms of sej of building materials relative to their quantity and their transformity. Transformity is accounted for each material assessing all steps of the process from their origin to their provision (i.e. from their extraction, to their final production). Building materials are therefore evaluated through the emergy analysis in order to give a measure of their environmental impact and their use in the building industry.

References for transformities used are: $a$, Simoncini [10]; $b$, Buranakarn [9]; $c$, Brown and Arding [11]; $d$, Odum [4]; e, Odum et al [12].

Table 1: $\quad$ Emergy flows of raw materials in the building.

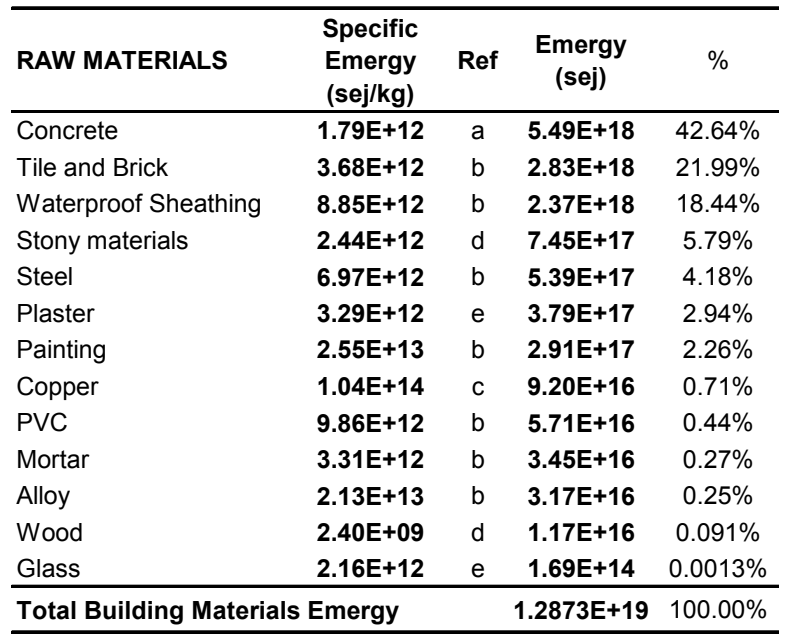

Materials have been aggregated into building structural parts, as shown in the building metric computation document, and emergy has been assessed for each part. In Table 2, the accounting of emergy flows of a building structural part, namely the external skin, has been presented, as an example.

In Table 3, results from the emergy analysis of the building are shown. Emergy flows are relative to each component and structural part in the building manufacturing process. 
Table 2: $\quad$ Emergy flows in a building structural part: the external skin.

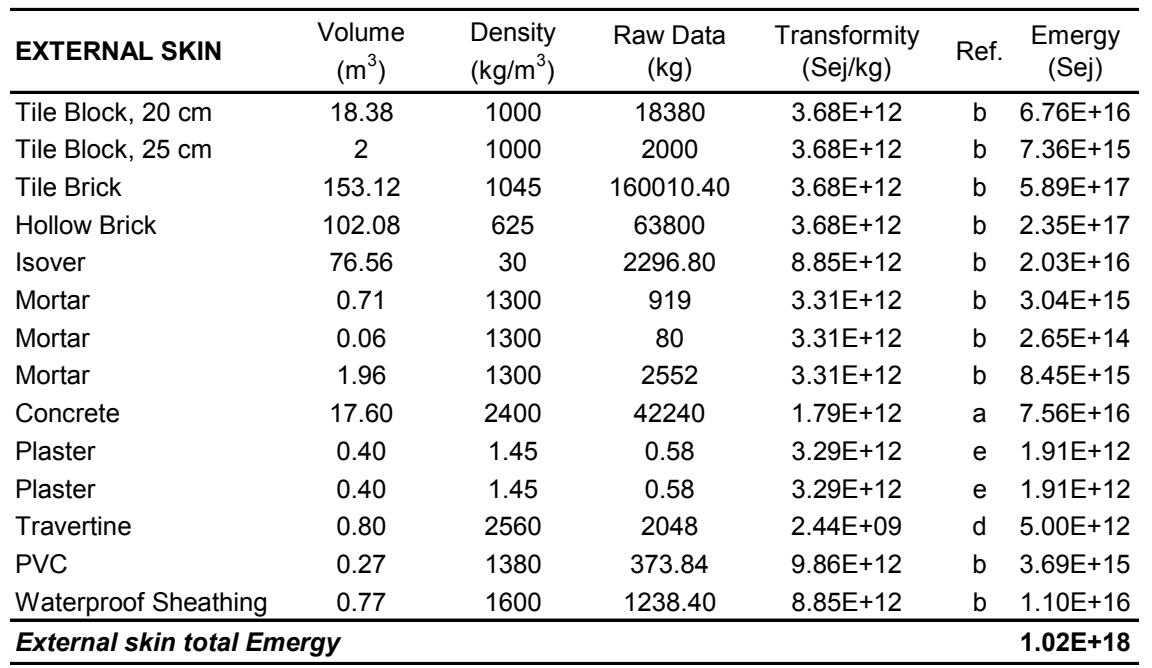

Table 3: $\quad$ Emergy flows aggregated into building structural parts.

\begin{tabular}{lcc}
\hline BUILDING STRUCTURAL PARTS & $\begin{array}{c}\text { Emergy } \\
\text { (sej) }\end{array}$ & $\%$ \\
\hline Solar radiation & $\mathbf{1 . 5 0 E + 1 7}$ & $0.79 \%$ \\
Land use (soil erosion) & $\mathbf{1 . 5 0 E + 1 1}$ & $0.00 \%$ \\
Building yard installation & $\mathbf{5 . 9 5 E + 1 6}$ & $0.32 \%$ \\
Basement & $\mathbf{2 . 2 2 E + 1 8}$ & $11.78 \%$ \\
Building frame & $\mathbf{2 . 0 0 E + 1 8}$ & $10.60 \%$ \\
External skin (facades) & $\mathbf{1 . 0 2 E + 1 8}$ & $5.41 \%$ \\
Floors & $\mathbf{5 . 0 8 E + 1 8}$ & $26.89 \%$ \\
Roof & $\mathbf{1 . 0 5 E + 1 8}$ & $5.57 \%$ \\
Partitions and other internal works & $\mathbf{1 . 0 7 E + 1 8}$ & $5.66 \%$ \\
Coating and details & $\mathbf{2 . 3 2 E + 1 7}$ & $1.23 \%$ \\
Windows and doors & $\mathbf{4 . 4 7 E + 1 6}$ & $0.24 \%$ \\
Sheet-metal works & $\mathbf{9 . 2 0 E + 1 6}$ & $0.49 \%$ \\
Drainage System & $\mathbf{5 . 4 7 E + 1 6}$ & $0.29 \%$ \\
Maintenance & $\mathbf{5 . 6 7 E + 1 8}$ & $30.06 \%$ \\
Human work & $\mathbf{1 . 3 0 E + 1 7}$ & $0.69 \%$ \\
\hline Total Buinding Emergy & $\mathbf{1 . 8 9 E + 1 9}$ & $100.00 \%$ \\
\hline
\end{tabular}

Results show the importance of each building structural part in terms of natural capital investment for building manufacturing. Results are shown in terms of emergy flows.

- Structural parts such as basement and building frame are about $23 \%$ of the whole emergy use for building manufacturing.

- Floors are about $27 \%$ of the total emergy flow. 
- The whole external covering of the building, that is the external skin (facades) and the roof, is about $11 \%$ of the total emergy flow.

- Internal works, such as partitions, coating and other details, are about $6 \%$ of the total emergy flow.

- Maintenance has been assessed according to the lifetime of structural parts and is about $30 \%$ of the total emergy flow (considering a building has a 50 years mean lifetime).

This detailed description based on the emergy analysis enables to evaluate the use of structural elements, technologies and materials in buildings in order to make choices in the executive project even before manufacturing the building. This analysis also works to compare possible scenarios and valuate different technologies and materials and their effects on energetic efficiency and environmental impacts.

In Table 4, consumptions of electricity, gas and water in building lifetime (50 years) are presented. These emergy flows are due to housing.

Table 4: $\quad$ Emergy flows of housing.

\begin{tabular}{lcccc}
\hline RESOURCE USE & Quantity & Unit & $\begin{array}{c}\text { Transformity } \\
\text { (Sej/unit) }\end{array}$ & Emergia (Sej) \\
\hline Electric Energy & $3.09 \mathrm{E}+11$ & $\mathrm{~J}$ & $2.07 \mathrm{E}+05$ & $\mathbf{6 . 4 0 \mathrm { E } + 1 6}$ \\
Gas Heating & $8.22 \mathrm{E}+08$ & $\mathrm{~J}$ & $6.72 \mathrm{E}+04$ & $\mathbf{5 . 5 2 E + 1 3}$ \\
Water Supply & $1.58 \mathrm{E}+06$ & $\mathrm{~kg}$ & $1.95 \mathrm{E}+09$ & $\mathbf{3 . 0 9 E + 1 5}$ \\
\hline Yearly Emergy for Housing & & & & $\mathbf{6 . 7 1 E + 1 6}$ \\
\hline
\end{tabular}

Results have been obtained for two phases of buildings life: the building manufacturing process and the building use (housing). Results show the following values:

- the total emergy flow due to the building manufacturing and the building maintenance is $1.89 \times 10^{19}$ sej. An emergy flow $\left(1.32 \times 10^{19}\right.$ sej $)$ represents the investment in terms of natural capital to provide the building. This amount of emergy could be conceived as emergy stocked in the building structures (as distributed into each structural part). As shown in the energy system diagram buildings are stocks of emergy. A yearly emergy flow is also accounted $\left(5.67 \times 10^{18}\right.$ sej in 50 years) for building maintenance. This flow is spent to maintain the building emergy stock.

- The total emergy flow due to building use (housing) is $6.71 \times 10^{16} \mathrm{sej} / \mathrm{yr}$. In 50 years this value is $3.35 \times 10^{18}$ sej.

Thus buildings achieve a new meaning considering that flows of energy and materials used for building manufacturing (raw materials extractions, building materials production, constructive elements assembling) are stocked in the building structural parts and buildings represent a memory of all the resources used in the process to provide a final structure for housing. The project of a 
building has also a significant effect on the period in which the building is used and on the resource consumption that could be assessed in the form of a constant emergy inflow in time. This emergy inflow due to housing depends on buildings technical characters and the choice of a different technology can require a different investment in the phase of building manufacturing (for example a different technology for facades) but it can also change buildings performance in terms of resource consumption during their lifetime. Therefore, the emergy analysis of buildings could be used to evaluate the investment for different technologies in the phase of building manufacturing and their effects in terms of resource saving in the phase of building use (housing).

\section{Conclusions}

An emergy analysis has been applied to a building and an emergy evaluation of buildings manufacturing process, buildings maintenance and buildings use (housing) has been provided. This method enabled to achieve the following results:

- An accounting of resource used in the building manufacturing process according to the environmental cost of all the materials and energy inflows.

- $\quad$ Emergy flows have been accounted relative to building materials according to their quantity (mass) and their environmental cost (transformity). A hierarchy of building materials in terms of emergy use has been presented.

- An emergy based evaluation has been provided for each building structural part (basement, frame, floors, external skin, internal works, windows and doors, coating and details), giving a measure of their environmental relevance.

- An emergy flow relative to building maintenance has been accounted. It represents a flow of energy and matter that is required during the building lifetime to maintain the building and let it work in time.

- An emergy analysis has been applied to the phase of building use, namely housing, in terms of resource consumptions. Data on electricity, gas and water consumption has been collected and considered constant for a period of 50 years (mean building lifetime).

- Results have been obtained for the two phases of building manufacturing and building use (housing) and could be compared to each other. A comprehensive emergy balance has been provided.

This study of buildings sustainability based on emergy analysis seems to be a powerful tools for future evaluations in the field of building industry. The expected outcomes should give clear information, based on a rigorous environmental accounting method, to make choices towards a sustainable development. 


\section{References}

[1] Roodman D.M. and Lenssen N., A building Revolution: How ecology and health concerns are transforming construction. Worldwatch Institute, paper \#124, 1995.

[2] Stein R. G., Architecture and Energy. Anchor Press, New York. 1977.

[3] Odum H. T. \& Odum E.C., Energy basis for man and nature. McGraw Hill: London, 1981

[4] Odum H. T., Environmental accounting: emergy and environmental decision making. Chichester Wiley: New York, 1996

[5] Odum H.T., Environment, power and society. Wiley, New York, US, 1971.

[6] Odum H.T., Systems ecology. Wiley, New York, US, 1983.

[7] Brown M. T. and Buranakarn V., Emergy indices and ratios for sustainable material cycles and recycle options. Resources, Conservation and Recycling, 38 (1), 2003, 1-22.

[8] Meillaud F., Gay J.B. and Brown M.T., Evaluation of a building using the emergy method. Solar Energy, 79 (2), 2005, 204-212.

[9] Buranakarn V., Evaluation of recycling and reuse of building materials using the emergy analysis method. University of Florida, Ph.D. Thesis, 1998.

[10] Simoncini E., Implicazioni ambientali ed energetiche di materiali ed elementi costruttivi in un edificio: un'analisi emergetica. Tesi di Laurea, University of Siena, 2006.

[11] Brown M.T. and J.E. Arding, Transformity Working Paper, Center for Wetlands, University of Florida, 1991.

[12] Odum H.T., Brown M.T. and Williams S.B., Handbook of emergy evaluation: a compendium of data for emergy computation issued in a series of folios. Folio \#1 - Introduction and Global Budget. Center for Environmental Policy, University of Florida, Gainesville, FL, 2000. 